\title{
Vehicle to Grid Communication Standards Development, Testing and Validation - Status Report
}

K Gowri

R Pratt

F Tuffner

M Kintner-Meyer

September 2011

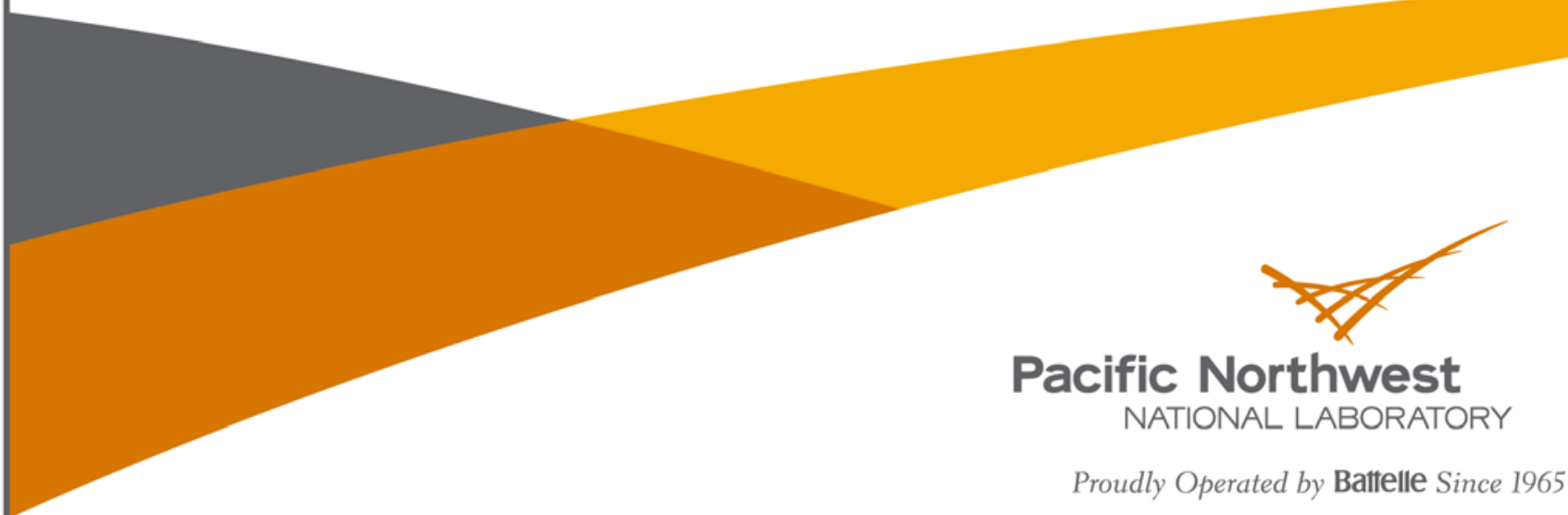




\title{
DISCLAIMER
}

This report was prepared as an account of work sponsored by an agency of the United States Government. Neither the United States Government nor any agency thereof, nor Battelle Memorial Institute, nor any of their employees, makes any warranty, express or implied, or assumes any legal liability or responsibility for the accuracy, completeness, or usefulness of any information, apparatus, product, or process disclosed, or represents that its use would not infringe privately owned rights. Reference herein to any specific commercial product, process, or service by trade name, trademark, manufacturer, or otherwise does not necessarily constitute or imply its endorsement, recommendation, or favoring by the United States Government or any agency thereof, or Battelle Memorial Institute. The views and opinions of authors expressed herein do not necessarily state or reflect those of the United States Government or any agency thereof.

\author{
PACIFIC NORTHWEST NATIONAL LABORATORY \\ operated by \\ BATTELLE \\ for the \\ UNITED STATES DEPARTMENT OF ENERGY \\ under Contract DE-AC05-76RL01830
}

Printed in the United States of America

Available to DOE and DOE contractors from the Office of Scientific and Technical Information,

P.O. Box 62, Oak Ridge, TN 37831-0062; ph: (865) 576-8401 fax: (865) 576-5728 email: reports@adonis.osti.gov

\begin{abstract}
Available to the public from the National Technical Information Service, U.S. Department of Commerce, 5285 Port Royal Rd., Springfield, VA 22161 ph: (800) 553-6847 fax: (703) 605-6900

email: orders@ntis.fedworld.gov online ordering: http://www.ntis.gov/ordering.htm
\end{abstract}

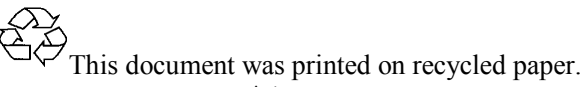




\title{
Vehicle to Grid Communication Standards Development, Testing and Validation - Status Report
}

\author{
K Gowri \\ R Pratt \\ F Tuffner \\ M Kintner-Meyer
}

September 2011

Prepared for

the U. S. Department of Energy

under Contract DE-AC05-76RL01830

Pacific Northwest National Laboratory

Richland, Washington 99352 


\section{Executive Summary}

Pacific Northwest National Laboratory (PNNL) actively participates in the Society of Automotive Engineers (SAE) standard development working group to accelerate the development of standards and protocols for vehicle to grid communications. P NNL staff contribute to the use case development, harmonization activities, testing and validation of standards requirements. This report summarizes the current status of vehicle to grid communication standards development activities and PNNL's role in accelerating the development, testing and validation of these standards. During FY11, PNNL contributions are focused on testing and validation related to J2931 standard for digital communication performance requirements, and the development of $\mathrm{J} 2836 / 3$ and $\mathrm{J} 2836 / 5$ standards which are aimed at reverse energy power flow and customer to vehicle communication.

ANSI launched a new effort in March 2011 to develop a roadmap of standards needed and available for electric vehicles. PNNL began participating in the communication infrastructure and human machine interaction working groups to review standards and identify gaps. The first draft of roadmap will be available by December 2011.

PNNL worked with the Electric Power Research Institute (EPRI), Argonne National Laboratory (ANL) and Grid Interaction Tech Team (GITT) members to develop performance requirements for communication modules that can be deployed on vehicle and charging stations. As part of this project, PNNL developed a test plan, purchased hardware, and developed software for testing and validation of the standards requirements. An initial testing phase was completed by developing two power line communication modules and presenting the results presented to SAE J2931 committee. This test provides a framework for future technology evaluations and definition of data rate, error rate and latency.

Further testing of power line communication technologies will be continued in FY12 to support the J2931 standard. F ield testing and demonstration of vehicle to utility AMI network will be undertaken in partnership charging station manufacturers and utility partners to test end-to-end communication. In addition, PNNL will continue to provide SAE standard development support for J2847/3 and J2847/5, once the $\mathrm{J} 2836 / 3$ and $\mathrm{J} 2836 / 5$ standards are completed. 


\section{Acronyms}

$\begin{array}{ll}\text { ANL } & \text { Argonne National Laboratory } \\ \text { ANSI } & \text { American National Standards Institute } \\ \text { EPRI } & \text { Electric Power Research Institute } \\ \text { IEC } & \text { International Electrotechnical Commission } \\ \text { ISO } & \text { International Standards Organization } \\ \text { NIST } & \text { National Institute of Standards and Technology } \\ \text { PNNL } & \text { Pacific Northwest National Laboratory } \\ \text { SAE } & \text { Society of Automotive Engineers }\end{array}$




\section{Contents}

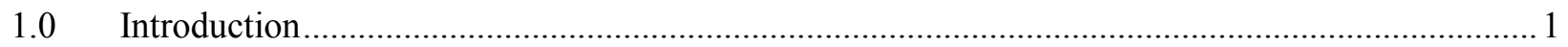

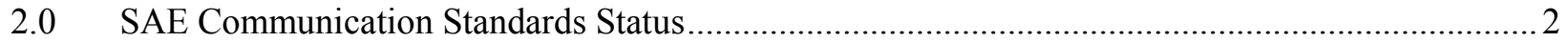

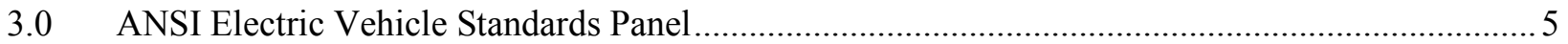

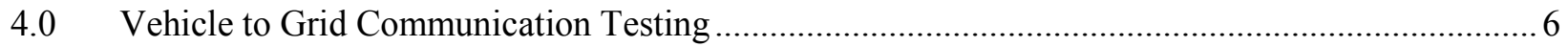

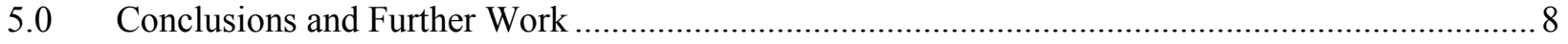

\section{Figures}

Figure 1: Summary of SAE Communication Standards (Scholer, 2011) ................................................ 3

Figure 2: Interaction/Dependency of SAE Communication Standards (Scholer, 2011)............................ 3

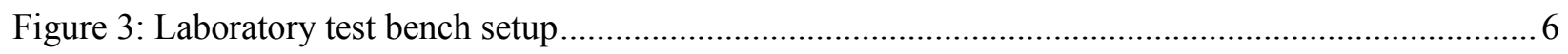




\subsection{Introduction}

In the US, more than 10,000 electric vehicles (EV) have been delivered to consumers during the first three quarters of 2011. A large majority of these vehicles are battery electric, often requiring 220 volt charging. Though the vehicle manufacturers and charging station manufacturers have provided consumers options for charging preferences, there are no existing communications between consumers and the utilities to manage the charging demand. There is also wide variation between manufacturers in their approach to support vehicle charging. There are in-vehicle networks, charging station networks, utility networks each using either cellular, Wi-Fi, ZigBee or other proprietary communication technology with no standards currently available for interoperability. The current situation of ad-hoc solutions is a major barrier to the wide adoption of electric vehicles. SAE, the International Standards Organization/International Electrotechnical Commission (ISO/IEC), ANSI, National Institute of Standards and Technology (NIST) and several industrial organizations are working towards the development of interoperability standards. PNNL has participated in the development and testing of these standards in an effort to accelerate the adoption and development of communication modules. 


\subsection{SAE Communication Standards Status}

SAE began the development of electric vehicle communication standards in 2009 with the initial focus on use-case development and communication messages for vehicle to utility communication. The first set of documents, SAE J2836/1 and J2847/1, were balloted and initially published in 2010, with revisions and adoption by the NIST Smart Grid Interoperability Panel in 2011 into their catalog of smart grid standards. In parallel, SAE has been developing several additional standards to define the communication protocol implementation requirements, DC charging, reverse energy power flow, telematics, customer to EV communications and wireless charging. Originally, SAE planned ten documents for communication standards, but this now has evolved into a four distinct categories totaling 21 standards. Figure 1 and 2 show the current list of standards in development and the interaction between them (Scholer, 2011) ${ }^{1}$. The significant progress of SAE standards development in 2011 includes the finalization of J2836/2, J2847/2, and $\mathrm{J} 2931 / 1$ documents for balloting and the beginning of work in J2836/3, J2836/4, J2836/5, and the addition of security, telematics and wireless charging communication standards.

\begin{tabular}{|c|c|}
\hline J2836 ${ }^{\mathrm{TM}}$ - General info (use cases) & J2847- Detailed info (messages) \\
\hline Dash 1 - Utility programs * & Dash 1 - Utility programs * \\
\hline Dash 2-Off-board charger communications** & Dash 2-Off-board charger communications ** \\
\hline Dash 3 - Reverse Energy Flow & Dash 3-Reverse Energy Flow \\
\hline Dash 4 - Diagnostics & Dash 4-Diagnostics \\
\hline Dash 5 - Customer to PEV and HAN/NAN & Dash 5 - Customer to PEV and HAN/NAN \\
\hline Dash 6-Wireless charging/discharging & Dash 6-Wireless charging/discharging \\
\hline J2931- Protocol (Requirements) & J2953- Interoperability \\
\hline Dash 1 - General Requirements*** & Dash 1 - General Reguirements \\
\hline Dash 2 - InBand Signaling (control Pilot) & Dasil 1 - gentelal nequiremints \\
\hline Dash 3 - NB OFDM PLC over pilot or mains & Dash 2 - Testing and Cert \\
\hline Dash 4 - BB OFDM PLC over pilot or mains & Dash 3 - \\
\hline Dash 5-Telematics & * Published \\
\hline Dash 6 - DSRC/RFID (wireless charging) & ** Being formatted for publishing \\
\hline Dash 7 - Security & $* * *$ In Ballot process \\
\hline
\end{tabular}

${ }^{1}$ Scholer, R., "SAE PEV Communication Task Force Status", Infrastructure Working Council Meeting, August 2011. 
Figure 1: Summary of SAE Communication Standards (Scholer, 2011) ${ }^{1}$

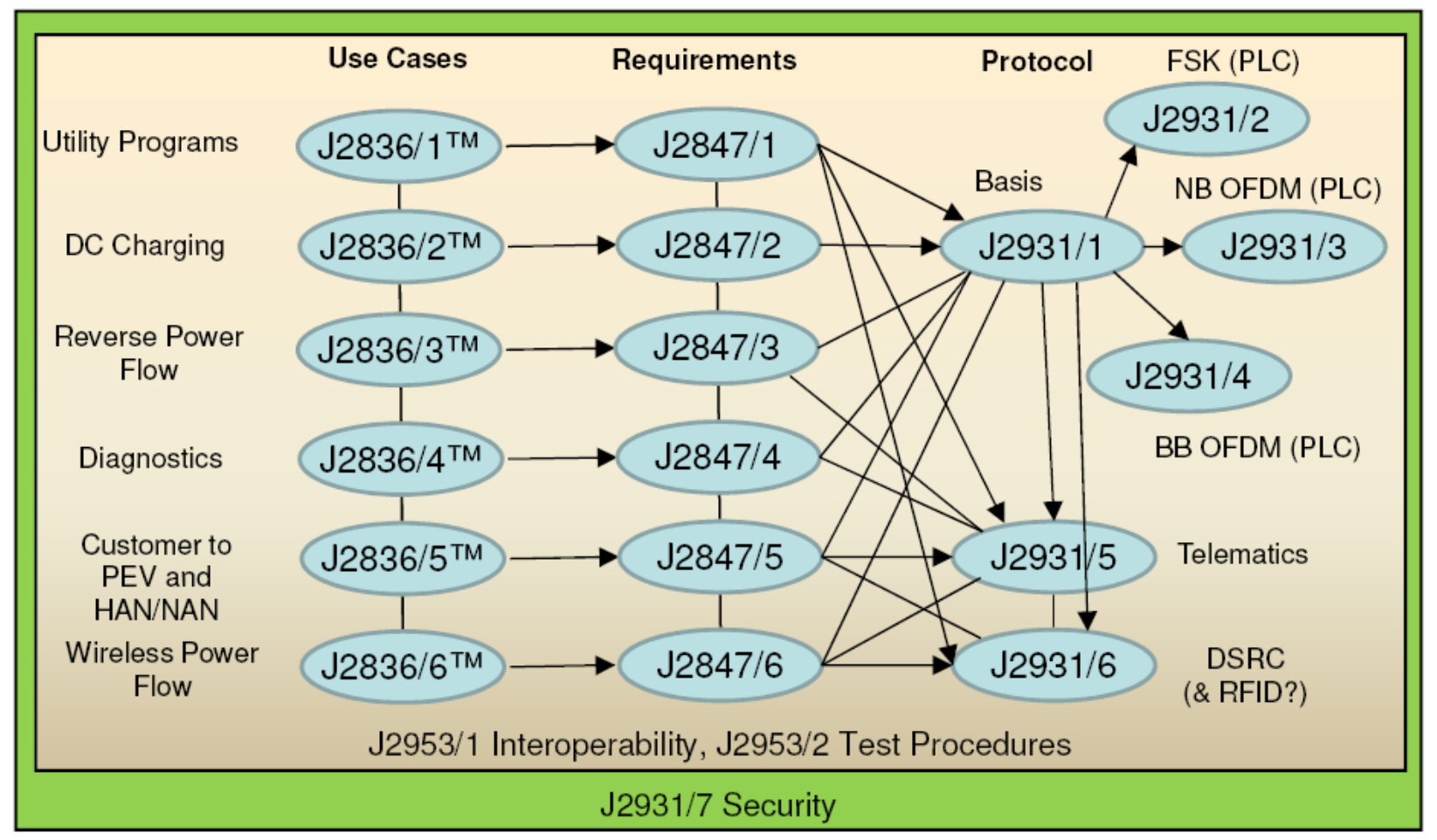

Figure 2: Interaction/Dependency of SAE Communication Standards (Scholer, 2011) ${ }^{1}$

The most critical standard for communication module development is J2931/1 which specifies the performance requirements and evaluation of power line communication technologies. EPRI has a requirements document, test plan and schedule, and coordinated this effort working with automobile manufacturers, utility partners and SAE hybrid committee participants. The current agreement is to test communication over control pilot (inband) using HomePlus GreenPHY and G3 to harmonize the requirements between SAE and ISO/IEC. In addition, G3 over mains will be tested as well. EPRI is coordinating the testing with ANL, PNNL and EPRI for all three communication options and based on the test plan for association, data rate, co-existence, latency and DC charging tests.

During FY11, PNNL primarily participated in the J2931 document review, and J2836/3 and J2836/5 document development activities.

1. The SAE document J2931 defines requirements for digital communications interface between EV and off-board device for energy transfer. These were reviewed and used in PNNL internal testing of power line communication modules. The smart charging implementation design in 
J2931 was implemented in the PNNL tests and validated for sequence of operation. Further testing of the communication modules will be coordinated with EPRI in FY12.

2. The primary focus of $\mathbf{J} 2836 / 3$ committee is to insure that the architecture of the Reverse Energy flow standard will meet IEEE 1547, NEC, UL 1741 and will be consistent with other standards. This standard has four primary use cases: V2G - Vehicle to Grid, V2H - Vehicle to Home, V2L - Vehicle to Load, and V2V - Vehicle to Vehicle. The major issues being addressed include: $\mathrm{V} 2 \mathrm{~L}$ - output voltage and frequency need to be controlled in vehicle, output power limiting circuitry needed; V2H - requires digital communication and transfer switches in the home are needed; V2G - no digital communication needed; etc. PNNL has been actively providing input and design review of the communication architecture, wiring and messages. This work has only recently begun and more active participation and support will be provided in FY12.

3. The J2836/5 document is aimed at defining the use cases for communication between the customer and vehicle using the home area network or neighborhood area network. PNNL prepared an initial discussion document of three possible architectures based on OpenHAN to focus the use case development. Two use cases of vehicle to utility though either telematics or home area networks are identified for further development. PNNL will continue to work on the use case development in FY12. 


\subsection{ANSI Electric Vehicle Standards Panel}

The ANSI Electric Vehicle Standards Panel (EVSP) was formed in April 2011 with the goal to develop a roadmap of standards and conformance assessment programs needed to accelerate the adoption of EV standards and rapid deployment of electric vehicles. The EVSP also plans to support U.S. policy and technical input for international coordination of standards and conformity programs.

The EVSP consists of seven working groups in three domains:

1. Vehicle Domain:
a. Energy Storage Systems Working Group
b. Vehicle Components Working Group
c. Vehicle User-interface Working Group

2. Infrastructure Domain:
a. Charging System Working Group
b. Infrastructure Communications Working Group
c. Infrastructure Installations Working Group

3. Support Services Domain:

a. Education and Training Working Group

The working groups have been meeting since June 2011, and are in the process of finalizing the first draft of the standards roadmap (version 1) by December 2011. PNNL is participating in two working groups related to communications, one in vehicle domain (vehicle user-interface) and another in infrastructure domain (infrastructure communications). The primary focus of the PNNL contribution is identifying gaps in standards that need to be addressed to enable smart charging and vehicle to grid communication. This effort is complementary to the SAE standards support. 


\subsection{Vehicle to Grid Communication Testing}

PNNL developed a test plan and lab test bench (Figure 3) for verification of J2847/1 standard. This test plan includes test cases, validation criteria, and certification requirements to verify reliability, robustness, repeatability, maximum communication distance, authentication, and security features of communication modules at the application layer level. The communications signals were subjected to varying conditions on the power line, similar to those expected in an actual vehicle battery charging application. These conditions included using a representative commercial vehicle battery charger (A123/Hymotion L5), a commercial charging station (Coulomb Technologies CT2100) with J1772 connector and cable, changing the length of 240VAC cable for power line communications, charging at different charge rates, and observing the immunity of the communications to in-band signal sources. Over 37 million messages were transmitted and 3.2 million messages were transmitted while charging. Following each charging cycle, the Hymotion battery was discharged using a $4.2 \mathrm{~kW}$ Aurora Inverter to the grid.

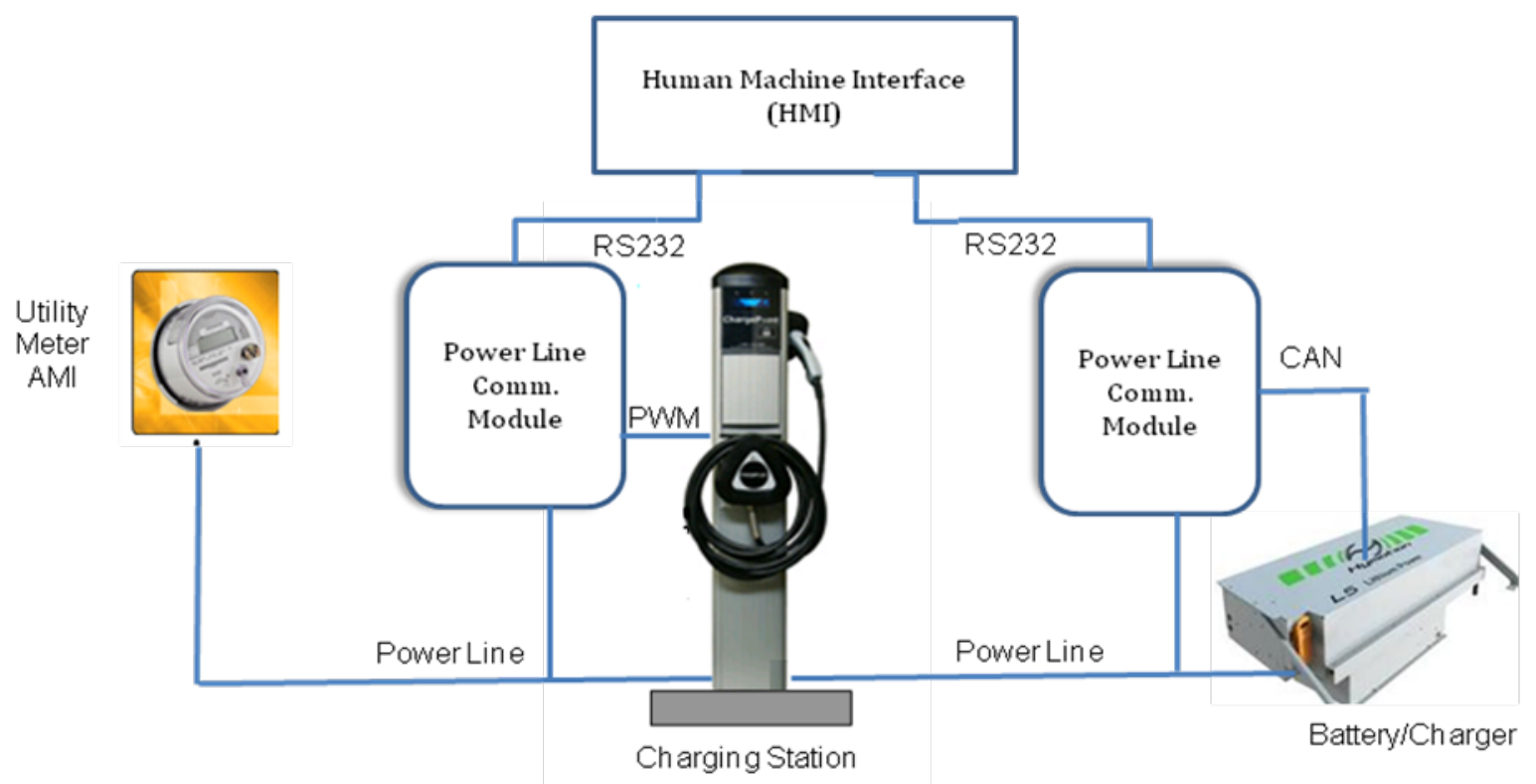

Figure 3: Laboratory test bench setup

The highest communication data rate necessary to implement SAE J2836 / J2847 vehicle to grid communications takes place when the vehicle connects to the charging station. The PEV ID, customer preferences, energy request, and energy schedule are communicated. Since the longest message (PEV 
ID) might be up to 20 characters, variable 5-character and variable 20 -character messages were used to test the communication speed.

For initial testing, two power line communication technologies from Echelon and Maxim were used based on availability of hardware and development support. Both the Echelon PL3170 and the MAXIM2991 Power Line Carrier modules provided reliable communications between the EVSE and PEV Charger. Both modules require a hardware interface between the PLC physical layer and the proposed SEP2.0 application layer. The results of testing are summarized below:

1. The Maxim's MAX2991 data rate varies from $2 \mathrm{Kbps}$ for very short messages to nearly $100 \mathrm{Kbps}$ for long messages. When operating the correct mode, the MAX2991 had less than 1 x 10-6 bit error rate.

2. The Echelon PL3170 data rate was consistently $1.9 \mathrm{Kbps}$. The PL3170 was not affected by interfering signals and its bit error rate was typically less than $28 \times 10-6$. A key finding is that only eight SAE J2847 messages need to be communicated between the PEV and EVSE during the highest data rate period.

3. Since both technologies need a hardware interface between the SEP2.0 application layer and the Power Line Carrier physical layer, the long SEP2.0 messages could be given aliases and communicated within 2 seconds.

The test plan and laboratory test setup provide all the required components for interoperability testing of communication over the mains. Further development is underway to test communications over control pilot and DC charging, in collaboration with SAE and EPRI. 


\subsection{Conclusions and Further Work}

During FY11, significant progress has been made in SAE standards development for defining the requirements for digital communications and in developing the test plan. However, there is a significant amount of development and testing that remains to be done in order to help the vehicle manufacturers and charging station manufacturers to develop communication modules critical for charge management by utilities. In FY12, PNNL will continue to work with EPRI in testing the application layer implementation of J2847/1 messages using the SEP 2.0 protocol and provide reference designs for industry adoption. Further work will also continue to support the SAE standards development for reverse energy power flow messages and customer to EV communication use cases. 
Dan Ton

United States Department of Energy, Office of Electricity

1000 Independence Ave, OE-10

Washington, DC 20585 


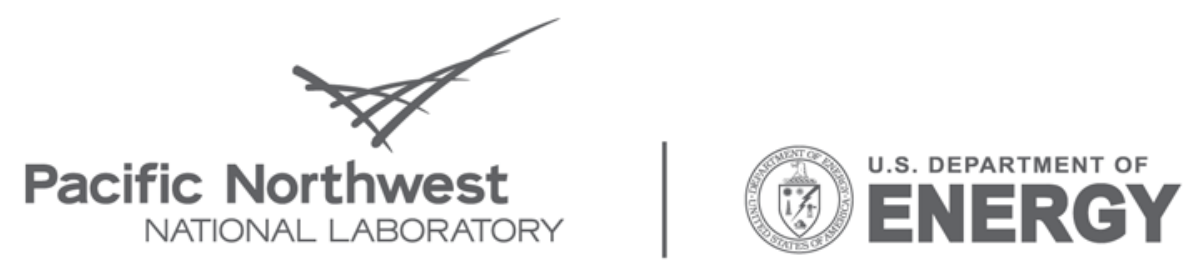

Proudly Operated by Battelle Since 1965

902 Battelle Boulevard

P.O. Box 999

Richland, WA 99352

1-888-375-PNNL (7665)

www.pnl.gov 